\title{
Microstructure and deformation behavior of the hot-rolled medium manganese steels with varying aluminum-content
}

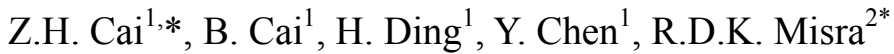 \\ ${ }^{1}$ School of Materials and Metallurgy, \\ Northeastern University, Shenyang, 110819, China \\ ${ }^{2}$ Laboratory for Excellence in Advanced Steel Research, \\ Department of Metallurgical, Materials and Biomedical Engineering, University of \\ Texas at El Paso, El Paso, TX 79968, USA
}

\begin{abstract}
$\underline{\text { Abstract }}$
We elucidate here the mechanistic contribution of the interplay between microstructural constituents and plastic deformation behavior in hot-rolled Fe-0.2C-11Mn-xAl steels containing 2-6 wt.\% Al. The decrease in austenite fraction with increase in Al-content was accompanied by decrease in tensile strength, while the $\delta$-ferrite content and ductility increased. $2 \mathrm{Al}$ steel was characterized by ultrahigh ultimate tensile strength (UTS) of $1407 \mathrm{MPa}$, while 6Al steel exhibited extremely high total elongation (TE) of $65 \%$. The superior ductility in $6 \mathrm{Al}$ steel is attributed to cumulative contribution of transformation induced plasticity (TRIP) effect and twinning induced plasticity (TWIP) effect. The increase in soft $\delta$-ferrite phase with low microhardness led to increase in TE and decrease in UTS and work hardening rate.
\end{abstract}

Keywords: austenite stability; $\delta$-ferrite; TRIP effect; work hardening; tensile properties

*Corresponding authors: R.D.K. Misra (dmisra2@utep.edu) Tel: 1-915-747-8679, Fax: 1-915-747-8036; Z.H. Cai (tsaizhihui@163.com); 


\section{Introduction}

The reduction in the weight of car is a priority for automobile manufacturers. To achieve this goal, light metals such as aluminum and magnesium alloys are being considered in preference to steels. However, these alloys cannot be used to make certain structure parts, such as pillar and bumper. It is, therefore, a feasible approach to reduce the density of advanced high strength steels through the addition of light elements such as aluminum and magnesium. According to the rough estimates, every $1 \%$ addition of $\mathrm{Al}$ contributes to $1.25 \%$ decrease in steel density $[1,2]$.

Low density steels can be categorized as ferrite-base [3], austenite-base [4, 5], and duplex-base (ferrite + austenite) [6-8]. Ferritic low density steels generally have relatively high $\mathrm{Al}$-content. It is reported that ferritic steels can have a maximum of 11 wt. $\%$ of $\mathrm{Al}[3,9]$. The addition of $\mathrm{Al}$ stabilizes $\alpha$-ferrite, and facilitates the presence of $\delta$-ferrite during solidification $[10,11]$. The addition of $\mathrm{Mn}$ and $\mathrm{C}$ compensates the effect of $\mathrm{Al}$ on phase stability and ensures austenite formation. Austenitic low density steels have high Mn-content and C-content.

Fe-Mn-C ternary alloy system with medium Mn-content (5-12\%) and low C-content $(<0.2 \%)$ is potential candidate for automotive applications [12-14]. This class of steels exhibit high strength and good ductility combination, which is primarily derived from transformation-induced plasticity (TRIP) effect. To accomplish reduction in weight, recent studies focused on the addition of Al to medium-Mn TRIP steels. Moreover, excellent mechanical properties were obtained in Fe-Mn-C-Al alloy system. For example, Han et al. obtained tensile strength of 1095 
$\mathrm{MPa}$ and total elongation of $42 \%$ in Fe-10Mn-0.14C-1.5Al (wt.\%) steel [15]. Suh et al. obtained tensile strength of $1000 \mathrm{MPa}$ and ductility of $30 \%$ in Fe-6Mn- $0.1 \mathrm{C}-3 \mathrm{Al}$ (wt.\%) steel [16]. Similarly, Park et al. demonstrated excellent combination of high tensile strength of $949 \mathrm{MPa}$ and ductility of $54 \%$ in Fe-8Mn-0.23C-5.3Al [17].

It seems from the aforementioned studies and background that $\mathrm{Al}$ is a viable option in the development of low-density steels. However, the large addition of Al may introduce manufacturing difficulties during casting or hot rolling, which may be the result of precipitation of $\mathrm{Fe}_{3} \mathrm{Al}$ intermetallic compounds [18]. Thus, an optimum $\mathrm{Al}$ content is required to optimize weight reduction and mechanical properties, and alleviate manufacturing difficulties. The objective of the study is aimed at elucidating the effect of Al-content on the microstructure, mechanical properties and deformation behavior in hot-rolled Fe-11Mn-0.2C-xAl steels.

\section{Experimental}

The nominal chemical composition of experimental steels (in wt. \%) was Fe-11Mn-0.2C-2Al (2Al steel), Fe-11Mn-0.2C-4Al (4Al steel) and Fe-11Mn-0.2C-6Al (6Al steel). The actual chemical composition of the three experimental steels are listed in Table 1 . The ingots were cast using a vacuum furnace and heated at $1200^{\circ} \mathrm{C}$ for $2 \mathrm{~h}$ and hot forged to rods of section size $\sim 100 \mathrm{~mm} \times 30$ $\mathrm{mm}$, followed by air cooling to room temperature. Subsequently, the rods were soaked at $1200^{\circ} \mathrm{C}$ for $2 \mathrm{~h}$, and hot rolled to $4 \mathrm{~mm}$ thickness in the temperature range of $1150-850^{\circ} \mathrm{C}$, and finally air cooled to ambient temperature.

The experimental steels were subjected to quenching and tempering (Q\&T) heat 
treatment, which was envisioned by us as an alternative and effective heat treatment [19-21]. First, they were annealed in the two-phase region or austenite region for $1 \mathrm{~h}$, followed by water quenching. Second, the quenched samples were tempered at $200^{\circ} \mathrm{C}$ for $20 \mathrm{~min}$ and air cooled to ambient temperature. Tempering was helpful in relieving the internal stress, but more importantly it improved the stability of austenite through the diffusion of $\mathrm{C}$ from $\delta$-ferrite to austenite [21].

Tensile specimens with a width of $12.5 \mathrm{~mm}$ and a gauge length of $50 \mathrm{~mm}$ were machined from the heat-treated sheets with the tensile axis parallel to the prior rolling direction. Tensile tests were carried out at room temperature using a universal testing machine (SANSCMT5000) at a constant crosshead speed of $3 \mathrm{~mm} \cdot \mathrm{min}^{-1}$. The specification for the tensile specimen used was Chinese national standard GB/T 228 - 2002, which is equal to ISO 6892:1998. The samples were etched with $25 \%$ sodium bisulfite solution. Microstructural examination was carried out using optical microscope $(\mathrm{OM})$, electron microprobe analysis (EMPA) and transmission electron microscope (TEM). Microhardness measurement was carried out by Vicker hardness tester. The selected pressure was $50 \mathrm{gf}$, and the holding time was $10 \mathrm{sec}$. The volume fraction of austenite was determined by $\mathrm{X}$-ray diffraction (XRD) with $\mathrm{CuK} \alpha$ radiation using direct comparison method [22], involving the use of integrated intensities of $(200)_{\alpha}$ and $(211)_{\alpha}$ peaks and those of $(200)_{\gamma},(220)_{\gamma}$ and $(311)_{\gamma}$ peaks. The volume fraction of austenite $\mathrm{V}_{\mathrm{A}}$ was calculated using equation [23]:

$\mathrm{V}_{A}=1.4 \mathrm{I}_{\gamma} /\left(\mathrm{I}_{\alpha}+1.4 \mathrm{I}_{\gamma}\right)$

where $I_{\gamma}$ is the integrated intensity of austenite and $I_{\alpha}$ is the integrated intensity of 
phases with body-centered cubic structure.

\section{Results}

\subsection{Microstructure}

SEM micrographs of as-hot-rolled steels are presented in Fig. 1. The microstructural constituents in $2 \mathrm{Al}$ steel consisted of martensite and austenite, while in $4 \mathrm{Al}$ steel besides martensite and austenite, $\delta$-ferrite was also present. In $6 \mathrm{Al}$ steel, lamellar austenite was present between the adjacent $\delta$-ferrite stripes. Fig. 2 illustrates the microstructure of hot rolled $2 \mathrm{Al}$ and $4 \mathrm{Al}$ steels heat treated at different temperatures, and Fig. 3 describes the microstructure of $6 \mathrm{Al}$ steel quenched at $650^{\circ} \mathrm{C}$, $850{ }^{\circ} \mathrm{C}, 950^{\circ} \mathrm{C}$ and $1000^{\circ} \mathrm{C}$, respectively, followed by tempering at $200^{\circ} \mathrm{C}$. The microstructural constituents of the experimental steels as a function of quenching temperature are summarized in Table 2 . The microstructural constituents in $2 \mathrm{Al}$ steel and $4 \mathrm{Al}$ steel varied with the quenching temperature, especially the austenite fraction, which was confirmed by XRD. In contrast to $2 \mathrm{Al}$ and $4 \mathrm{Al}$ steels, the microstructural constituents of $6 \mathrm{Al}$ steel consisted mainly of austenite and $\delta$-ferrite stripes in the absence of martensite and $\alpha$-ferrite.

The variation in the volume fraction of austenite obtained from XRD is summarized in Fig. 4. $2 \mathrm{Al}$ steel had a high austenite fraction of $\sim 80 \%$ in the temperature range of $600-700^{\circ} \mathrm{C}$, followed by a dramatic decrease to $\sim 25 \%$, when quenching was carried out in the temperature range of $750-850{ }^{\circ} \mathrm{C}$ because of martensitic transformation, as evidenced in Fig. $2 b$. It is further estimated that $\sim 55 \%$ martensite was developed during quenching. Similar trend in the austenite fraction 
was observed in $4 \mathrm{Al}$ steel. $4 \mathrm{Al}$ steel had lower austenite content $(\sim 70 \%)$ than $2 \mathrm{Al}$ steel. The austenite fraction in $4 \mathrm{Al}$ steel was deduced to $\sim 10 \%$ when quenching in the range of $850-900^{\circ} \mathrm{C}$ because of martensitic transformation (Fig. 2d). In contrast, the austenite fraction in 6Al steel was not strongly governed by the quenching temperature and was $\sim 50 \%$ in the range of $650-1000^{\circ} \mathrm{C}$. Comparing the microstructure in Figs. 2 and 3, it is obvious that the fraction of $\delta$-ferrite increased with increase in $\mathrm{Al}$ content, considering that $\mathrm{Al}$ is ferrite stabilizer. Moreover, as summarized in Table 2, there is no $\delta$-ferrite in $2 \mathrm{Al}$ steel, and the fraction of $\delta$-ferrite in $4 \mathrm{Al}$ steel estimated by Image-Pro Plus software was $\sim 5 \%$. The microstructural constituents in $6 \mathrm{Al}$ steel consisted of $\delta$-ferrite and austenite, and it was confirmed by XRD results (Fig. 4) that the austenite fraction was $\sim 50 \%$, thus, the fraction of $\delta$-ferrite was $\sim 50 \%$.

\subsection{Mechanical properties}

The mechanical properties of the three steels are summarized in Fig. 5. It may be seen that $6 \mathrm{Al}$ steel had the lowest ultimate tensile strength (UTS), but total elongation (TE) was the best among the three steels. In $6 \mathrm{Al}$ steel, there was only a small decrease in UTS in the range of $650-1000^{\circ} \mathrm{C}$, while the TE decreased markedly from $65 \%$ to $37 \%$. In $4 \mathrm{Al}$ steel, the UTS increased continuously with increased temperature up to $850^{\circ} \mathrm{C}$, whereas TE reached maximum at $750^{\circ} \mathrm{C}$ and then decreased with increased temperature. Compared to the other two steels, 2Al steel had significantly high UTS of $1370-1450 \mathrm{MPa}$. However, it was intriguing to note that $2 \mathrm{Al}$ steel with the highest austenite content (Fig. 4) had lowest TE of 22-32\% among the three steels when quenched from their respective two-phase region. 
The underlying reasons for the variation in tensile properties in $2 \mathrm{Al}$ steel are mainly related to TRIP effect and Portevin-Le Chatelier (PLC) effect, and for 4Al steel to the fraction and stability of austenite, as demonstrated in our previous studies $[19,24]$. To understand the effect of $\mathrm{Al}$ content on the microstructure and mechanical property, two intriguing aspects in $6 \mathrm{Al}$ steel need specific attention: (a) the relationship between microstructure and tensile properties, and (b) extended stress plateau in the strain-stress plots (Fig. 6a) are discussed in the next section.

\section{Discussion}

\subsection{Austenite stability and tensile properties}

As demonstrated in Fig. 5, the UTS and the TE of 6Al samples decreased with increase in quenching temperature. Given that the austenite fraction in $6 \mathrm{Al}$ samples was similar (Fig. 4), we envisage that austenite stability decreased with increase in quenching temperature. In order to confirm the hypothesis, the austenite fraction of 6Al samples after tensile fracture was measured by XRD. As shown in Fig. 4, samples quenched from $650^{\circ} \mathrm{C}$ and $1000^{\circ} \mathrm{C}$ (henceforth nominated as 6Al-650 and 6Al-1000) had similar austenite fraction both before tensile test and after tensile fracture. However, 6Al-650 had superior ductility (64.7\%) and marginally higher UTS (659 $\mathrm{MPa}$ ) than $6 \mathrm{Al}-1000(37.5 \%, 602 \mathrm{MPa})$. Thus, it is deduced that austenite in 6A1-1000 with low stability transformed at a smaller strain leading to low UTS and ductility. It is further inferred that austenite stability decreased with increase in quenching temperature. In the attempt to quantify this behavior, equation (2) was used $[25,26]:$ 
$f_{\gamma}=f_{\gamma 0} \exp (-k \varepsilon)$

In equation (2), $f_{\gamma 0}, f_{\gamma}$ and $k$ are initial austenite fraction, austenite fraction at strain $\varepsilon$, and mechanical stability of austenite, respectively. A higher value of $k$ corresponds to lower austenite stability. For each sample, the initial austenite fraction $\left(f_{\gamma 0}\right)$ and the austenite fraction $\left(f_{\gamma}\right)$ could be obtained from XRD results, when it was tensile fractured at strain $\varepsilon$ (Fig. 4). Inserting these parameters into Eq.2, the value of $k$ was determined. Fig. $6 \mathrm{~b}$ shows that the estimated value of $k$ increases with quenching temperature.

It is well known that grain size and alloying element $(\mathrm{C}$ and $\mathrm{Mn})$ play a key role in austenite stability. Moreover, austenite with larger grain size preferentially transforms into martensite [27]. Fig. 7 demonstrates the proportion of the lamellar austenite as a function of lamellar thickness in 6Al-650 and 6Al-1000 samples. The data is calculated by using the grid method. It is clear that $6 \mathrm{Al}-1000$ sample had higher fraction of austenite in the lamellar thickness range of 5-10, 10-15 and $\geq 15 \mu \mathrm{m}$, respectively. Thus, increase of lamellar thickness in austenite is most likely to be one of the reasons. Furthermore, the influence of $\mathrm{Mn}$ and $\mathrm{C}$ needs to be considered. The Mn and Al-content of austenite were measured by EPMA / EDS from more than 20 randomly selected austenite grains and average values were calculated. The C-content of austenite was calculated from the following equation: [28]

$\alpha_{\gamma}=0.3556+0.00453 X_{\mathrm{C}}+0.000095 X_{\mathrm{Mn}}+0.00056 X_{\mathrm{Al}}$

where $X_{\mathrm{C}}, X_{\mathrm{Mn}}$, and $X_{\mathrm{Al}}$ are concentration of carbon, manganese, and aluminum in austenite, respectively, in wt.\%. $\alpha_{\gamma}$ is the lattice parameter of the austenite, in $\mathrm{nm}$, 
which can be determined by XRD using Cohen's method [29]. As demonstrated in Table 3, the C-content decreased with increase in quenching temperature, whereas the Mn-content did not show any significant difference. Based on the aforementioned observation, increase of lamellar thickness and decrease of C-content in austenite led to decrease in austenite stability, which led to the decrease in TE and UTS.

\subsection{Work hardening behavior}

As shown in Fig. 6a, the strain-stress curves of $6 \mathrm{Al}$ steel are characterized by a stress plateau, and the length of plateau decreases with increase in quenching temperature. The reason underlying the superior ductility of $6 \mathrm{Al}$ samples can be further elucidated by studying the work-hardening behavior. The work hardening rate (WH) obtained from the tensile tests for 6Al-650, 6Al-750, 6Al-850 and 6Al-1000 samples are presented in Fig. 8. The samples exhibit three stages of WH evolution: (1) WH rapidly decreases; (2) WH slowly decreases; and (3) WH remains nearly constant for a strain range.

The work hardening behavior of $6 \mathrm{Al}$ samples is different from $2 \mathrm{Al}$ and $4 \mathrm{Al}$ steels. The $\mathrm{WH}$ of $2 \mathrm{Al}$ sample quenched from $650^{\circ} \mathrm{C}$ and $4 \mathrm{Al}$ sample quenched from $800^{\circ} \mathrm{C}$ (henceforth referred as $2 \mathrm{Al}-650$ and $4 \mathrm{Al}-800$ respectively) are presented in Fig. 9. The WH first decreases (stage 1), then increases (stage 2), and finally decreases with fluctuations. The first stage is mainly associated with the deformation of ferrite, and the second intermediate stage characterized by increase in $\mathrm{WH}$ is attributed to TRIP effect $[25,30]$. In our previous study on 4Al-800, austenite with different degree of stability was responsible for the TRIP effect that occurred discontinuously, 
which led to fluctuation in work hardening rate curves [31, 32], and serrations in 2Al-650 were related to PLC effect and discontinuous TRIP effect [24].

The relationship between work hardening ability and deformation mechanisms in 6Al steel can be further elucidated through the interrupted tensile tests. Fig. 10 shows the variation in volume fraction of austenite as a function of engineering strain measured by XRD for 6Al-650 sample. The austenite fraction remained almost unchanged during the initial stage of tensile test, corresponding to a rapid decrease in WH. In the strain range of $0.05-0.40$, the austenite fraction decreased linearly. Because of TRIP effect, WH slowly decreased and then remained nearly constant with increase in strain. However, it is unusual that the austenite fraction remained nearly constant from strain of 0.40 until fractured $(0.65)$, and the corresponding WH remained almost constant instead of decreasing with strain. Thus, besides TRIP effect, there must be another deformation mechanism that was dominant in stage 4 .

Detailed microstructural evolution of 2Al-650 samples tensile strained to $0.2,0.4$ and fractured, is presented in TEM micrographs (Fig. 11). At strain of 0.2, some deformation twins were observed, and the spacing between the twins was large. The number of deformation twins increased with strain and the spacing was reduced at strain of 0.4 , and in tensile fractured sample, high density of deformation twins were observed. Thus, it is inferred that while TRIP effect was the dominant deformation mechanism in the strain range of $0-0.4$, but twinning induced plasticity (TWIP) effect also played a major role from strain of 0.4 until fracture. It is clear from Fig. 8 that the corresponding strain and the slope of stage 2 increased with increase in quenching 
temperature, while the length of $\mathrm{WH}$ plateau corresponding to stage 3 was a consequence of combined effect of TRIP and TWIP effect, which decreased with increase in quenching temperature.

\subsection{The effect of Al content on microstructure and mechanical property}

As demonstrated in Fig. 5, UTS decreases with increase in Al content, but the TE increases with the increase in Al content. Based on our previous work $[19,24]$ and the above discussion, the mechanical properties of the three steels are related to TRIP effect. Considering 2Al-650, 4Al-800 and 6Al-650 for comparison because they exhibited the best combination of tensile properties, the microstructural constituents of the three samples are listed in Table 2. Fig. 12 describes the microstructure of 2Al-650, 4Al-800 and 6Al-650 samples after tensile fracture. Moreover, according to the XRD results, the austenite fraction in 2Al-650, 4Al-800 and 6Al-650 samples was $84 \%, 69 \%$ and $47 \%$, respectively, and was deduced to be $35 \%, 16 \%$ and $22 \%$, respectively, after tensile fracture. Thus, the fraction of martensite transformed from austenite during tensile deformation in the three samples was $49 \%, 53 \%$ and $25 \%$, respectively. Therefore, the lowest TRIP amount in 6Al-650 sample is responsible for the lowest tensile strength.

In general, TRIP effect increases the work hardening rate because of strain-induced transformation of austenite to martensite. Furthermore, TRIP effect enhances the ductility because it delays the onset of necking. However, there is some contradiction on comparing the mechanical properties and $\mathrm{WH}$ of the three samples. First, the martensite transformed from austenite during tensile test was maximum in 
4Al-800 sample, but its UTS (1082 $\mathrm{MPa})$ and WH were significantly less than 2A1-650 (UTS: $1407 \mathrm{MPa}$ ). Second, the occurrence of martensitic transformation was continuous in the strain range of 0-0.4 in 6Al-650 sample (Fig. 10). However, the WH decreased first and then remained at a low value ( 1000 MPa). Furthermore, although the TRIP effect in 6Al-650 was the weakest, the ductility was the best among all the samples. Thus, the role of TRIP effect governing in tensile properties was overstated. Some other factors need to be considered.

The influence of ferrite in tensile properties is often ignored in medium Mn-content TRIP steel. As shown in Figs. 2-4, $\alpha$-ferrite fraction increased with Al-content (in the range of 2-4\%) and when the Al-content increased to $6 \%$, a large amount of $\delta$-ferrite $(\sim 50 \%)$ was obtained, and $\alpha$-ferrite was suppressed. Thus, it is inferred that the variation in tensile properties and $\mathrm{WH}$ among the three samples is related to the ferrite fraction. As shown in Fig. 2, some blocky austenite in 2Al and 4Al samples was divided by $\alpha$-ferrite into lamellar morphology with different thickness and length. It was further confirmed that $\mathrm{Mn}$ and $\mathrm{C}$ were non-uniformly distributed in lamellar austenite leading to discontinuous TRIP effect, which contributed to enhancement of strength and WH [21, 31-33]. However, based on the EPMA / EDS results, Mn and C were distributed uniformly in austenite in 6Al steel. Thus, discontinuous TRIP effect was not observed in 6Al steel because of the absence of $\alpha$-ferrite, which was one of the reasons for low UTS and WH in 6Al steel. Moreover, as shown in Table 4, $\alpha$-ferrite had a higher microhardness than $\delta$-ferrite, and the amount of $\delta$-ferrite increased with increase in Al-content. Therefore, the 
increase in soft phase of $\delta$-ferrite was related to increase in TE and decrease in UTS. It can be further deduced that stacking fault energy increased with increase in Al content, which contributed to the occurrence of TWIP effect in 6Al steel leading to superior ductility.

\section{Conclusions}

(1) Austenite fraction and tensile strength decreased with increase in Al content, while $\delta$-ferrite content and ductility increased with increase in Al content. 2Al-650 sample exhibited excellent combination of TE of 31.4\%, UTS of $1407 \mathrm{MPa}$. 6Al-650 sample demonstrated superior TE of $64.7 \%$ but low UTS of $659 \mathrm{MPa}$.

(2) Tensile strength and ductility of 6Al steel decreased with increase in quenching temperature. It was noted that increased lamellar thickness and the decreased C-content in austenite led to decrease in austenite stability, which led to decrease in TE and UTS. 6Al-650 sample with superior ductility is attributed to the cumulative contribution of TRIP effect and TWIP effect.

(3) When the Al-content was increased to $6 \%$, a high percentage of $\delta$-ferrite $(\sim 50 \%)$ was obtained, and $\alpha$-ferrite was suppressed. Because of the absence of $\alpha$-ferrite in 6Al steel, $\mathrm{Mn}$ and $\mathrm{C}$ were uniformly distributed in austenite. Thus, discontinuous TRIP effect was not observed in 6Al steel, which was one of the reasons for low UTS and WH in $6 \mathrm{Al}$ steel. Moreover, the increase in soft phase of $\delta$-ferrite led to increase in TE and decrease in UTS.

\section{Acknowledgements}

The present study was financially supported by the National Natural Foundation for 
Young Scientists of China (No: 51501035) and Chinese Postdoctoral Science Foundation (2015M580230 and 2016T90227). RDKM gratefully acknowledges support from National Science Foundation, USA through grant number DMR 1602080. 


\section{$\underline{\text { References }}$}

[1] H. Kim, D.W. Suh, N.J. Kim, Sci. Technol. Adv. Mater. 14 (2013) 01-11.

[2] M.D. Zhang, W.Q. Cao, H. Dong, J. Zhu, Mater. Sci. Eng. A 654 (2016) 193-202.

[3] R. Rana, C. Liu, and R.K. Ray, Scripta Mater. 68, 354 (2013).

[4] I. Jung, S.J. Lee, B.C.D. Cooman, Scr. Mater. 66 (2012) 729-732.

[5] K.T. Park, Scr. Mater. 68 (2013) 375-379.

[6] W.K. Choo and J.H. Kim, Acta Mater. 45, 4877 (1997).

[7] R. Rana, C. Liu, R.K. Ray, Acta Mater. 75 (2014) 227-245.

[8] Z.Q. Wu, H. Ding, H.Y. Li, M.L. Huang, F.R. Cao, Mater. Sci. Eng. A 584 (2013) $150-155$.

[9] A.C. Lilly, S.C. Deevi, and Z.P. Gibbs, Mater. Sci. Eng. A 258, 42 (1998).

[10] D.W. Suh, S.J. Park, C.S. Oh, S.J. Kim, Scripta Mater. 57 (2007) 1097

[11] S. Chatterjee, M. Murugananth, H.K.D.H. Bhadeshia, Mater. Sci. Technol. 23 (2007) 819 .

[12] M.J. Merwin, Mater. Sci. Forum. 539-543 (2007) 4327-4332.

[13] H.W. Luo, J. Shi, C. Wang, W.Q. Cao, X.J. Sun, H. Dong, Acta Mater 59 (2011) 4002-4014.

[14] J. Han, S.-J. Lee, J.-G. Jung, Y.-K. Lee, Acta Mater 78 (2014) 369-377.

[15] Qihang Han, Yulong Zhang, Li Wang, Metall. Mater. Trans. A 42A (2015)

1917-1926.

[16] D.W. Suh, S.J. Park, T.H. Lee, C.S. Oh, S.J. Kim, Metall. Mater. Trans. A 41 (2010) 397.

[17] S.-J. Park, B. Hwang, K.H. Lee, T.-H. Lee, D.-W. Suh, H.N. Han, Scr. Mater. 68 (2013) 365-369.

[18] R.G. Baligidad, U. Prakash, and A. Radhakrishna, Scripta Mater. 36, (1997) 667-671

[19] Z.H. Cai, H. Ding, X. Xue, Q.B. Xin, Mater. Sci. Eng. A 560 (2013) 388-395.

[20] Z.H. Cai, H. Ding, H. Kamoutsi, G.N. Haidemenopoulos, R.D.K. Misra, Mater. Sci. Eng. A 654 (2016) 359-367.

[21] Z.H. Cai, H. Ding, R.D.K. Misra, H. Kong, H.Y. Wu, Mater. Sci. Eng. A 595 (2014) 86-91.

[22] A.K. Srivastava, D. Bhattacharjee, G. Jha, N. Gope, S.B. Singh, Mater. Sci. Eng. A. 445-446 (2007) 549-557.

[23] A. Grajcar, H. Krzton. Journal of Achievements in Materials and Manufacturing Engineering, 35 (2009) 169-176.

[24] Z.H. Cai, H. Ding, R.D.K. Misra, S.Q. Qiguan, Mater. Sci. Eng. A 652 (2016) 205-211.

[25] J. Shi, X. Sun, M. Wang, W. Hui, H. Dong, and W. Cao, Scr. Mater., 2010, 63(8), p $815-818$

[26] S. Zhou, K. Zhang, Y. Wang, J.F. Gu, Y.H. Rong, Mater. Sci. Eng. A 528 (2011) 8006-8012.

[27] Y.S. Jung, Y.K. Lee, D.K. Matlock, M.C. Mataya, Met. Mater. Int. 17 (2011) $553-556$. 
[28] Van Dijk NH, Butt AM, Zhao L, Sietsma J, Offerman SE, Wright JP, Van der Zwaag S. Acta Mater. 2005; 53: 5439.

[29] M.U. Cohen, Rev. Sci. Instrum. 6 (1935) 68.

[30] A. Arlazarov, M. Goune', O. Bouaziz, A. Hazotte, G. Petitgand, and P. Barges, Mater. Sci. Eng. A, 2012, 542, p 31-39

[31] Z.H. Cai, H. Ding, R.D.K. Misra, H. Kong, Scr. Mater. 71 (2014) 5-8.

[32] Z.H. Cai, H. Ding, R.D.K. Misra, Z.Y. Ying, Acta Mater 84 (2015) 229-236.

[33] Z.C. Li, H. Ding, Z.H. Cai, Mater. Sci. Eng. A 639 (2015) 559-566. 


\section{Figure captions}

Fig. 1. SEM micrographs of three as-hot-rolled steels. (a) $2 \mathrm{Al}$ steel, (b) $4 \mathrm{Al}$ steel and (c) $6 \mathrm{Al}$ steel. (M: martensite, A: austenite, $\delta$-F: $\delta$-ferrite)

Fig. 2. SEM micrographs of the hot-rolled $2 \mathrm{Al}$ steel and $4 \mathrm{Al}$ steel quenched from different temperatures and then tempered at $200^{\circ} \mathrm{C}$. (a) $2 \mathrm{Al}-700^{\circ} \mathrm{C}$, (b) $2 \mathrm{Al}-750^{\circ} \mathrm{C}$, (c) $4 \mathrm{Al}-800^{\circ} \mathrm{C}$, (d) $4 \mathrm{Al}-850^{\circ} \mathrm{C}$. (A: austenite, M: martensite, $\alpha$-F: $\alpha$-ferrite, $\delta$-F: $\delta$-ferrite)

Fig. 3. Optical micrographs of $6 \mathrm{Al}$ steel quenched at (a) $650^{\circ} \mathrm{C}$, (b) $850^{\circ} \mathrm{C}$, (c) $950^{\circ} \mathrm{C}$, (d) $1000^{\circ} \mathrm{C}$, respectively, and then tempered at $200^{\circ} \mathrm{C}$. (A: austenite, $\delta$-F: $\delta$-ferrite)

Fig. 4. Measured austenite fraction of the experimental steels as a function of quenching temperature.

Fig. 5. Tensile properties of the three experimental steels. (a) ultimate tensile strength, (b) total elongation.

Fig. 6. Engineering strain-stress plots (a) and calculated $k$ parameter (b) of 6Al steel quenched at different temperatures.

Fig. 7. The percent of the lamellar austenite as a function of lamellar thickness in 6Al-650 and 6Al-1000 samples.

Fig. 8. Work hardening rate of $6 \mathrm{Al}$ samples quenched at different temperatures. (a) $650^{\circ} \mathrm{C}$, (b) $750^{\circ} \mathrm{C}, 850^{\circ} \mathrm{C}$ and $1000^{\circ} \mathrm{C}$ (S1: stage $1, \mathrm{~S} 2$ : stage 2 , and so on).

Fig. 9. Work hardening rate of 2Al-650 sample (a) and 4Al-800 samples (b) (S1: stage 1, S2: stage 2, and so on).

Fig. 10. Variation in austenite fraction in 6Al-650 sample subjected to interrupted tensile test. 
Fig. 11. TEM micrographs of 6Al-650 sample subjected to interrupted tensile test. (a) strained to 0.2 , (b) strained to 0.4 , (c) tensile fractured, (d) indexing on the spots of the selected area electron diffraction pattern of the austenite twins.

Fig. 12. SEM micrographs of $2 \mathrm{Al}-650,4 \mathrm{Al}-800$ and $6 \mathrm{Al}-650$ samples after tensile fracture. (a) 2Al-650, (b) 4Al-800, (c) 6Al-650. 


\section{Tables}

Table 1 Chemical composition (wt. \%) of three experimental steels.

Table 2 Microstructural constituents of the experimental steels

Table 3 Contents of alloying elements of austenite in 6Al samples

Table 4 Microhardness of constituent phases in different samples 

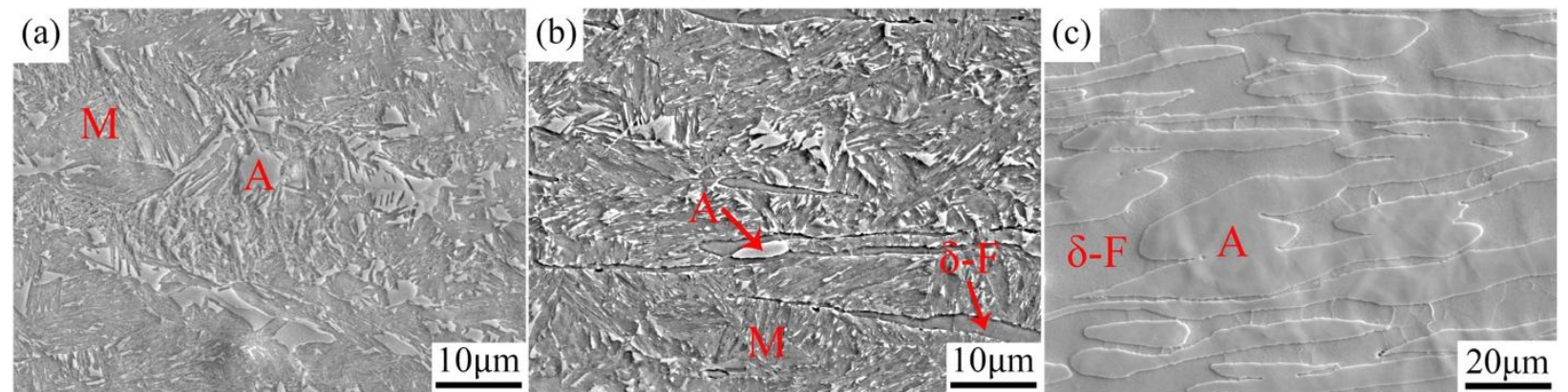

Fig. 1. SEM micrographs of three as-hot-rolled steels. (a) 2Al steel, (b) 4Al steel and (c) 6Al steel. (M: martensite, A: austenite, $\delta$-F: $\delta$-ferrite)
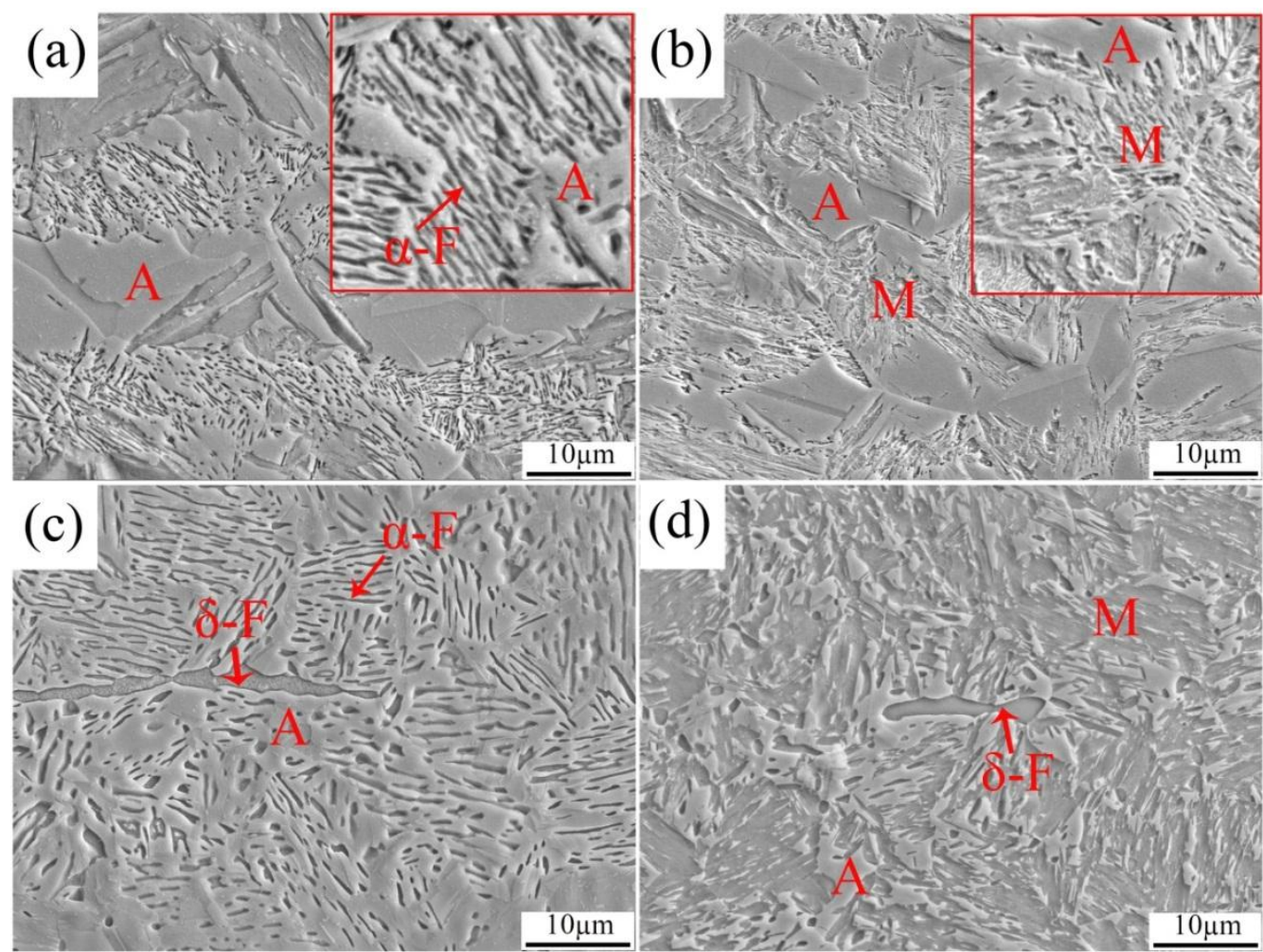

Fig. 2. SEM micrographs of the hot-rolled $2 \mathrm{Al}$ steel and $4 \mathrm{Al}$ steel quenched from different temperatures and then tempered at $200^{\circ} \mathrm{C}$. (a) $2 \mathrm{Al}-700^{\circ} \mathrm{C}$, (b) $2 \mathrm{Al}-750^{\circ} \mathrm{C}$, (c) $4 \mathrm{Al}-800^{\circ} \mathrm{C}$, (d) $4 \mathrm{Al}-850^{\circ} \mathrm{C}$. (A: austenite, M: martensite, $\alpha$-F: $\alpha$-ferrite, $\delta$-F: $\delta$-ferrite) 

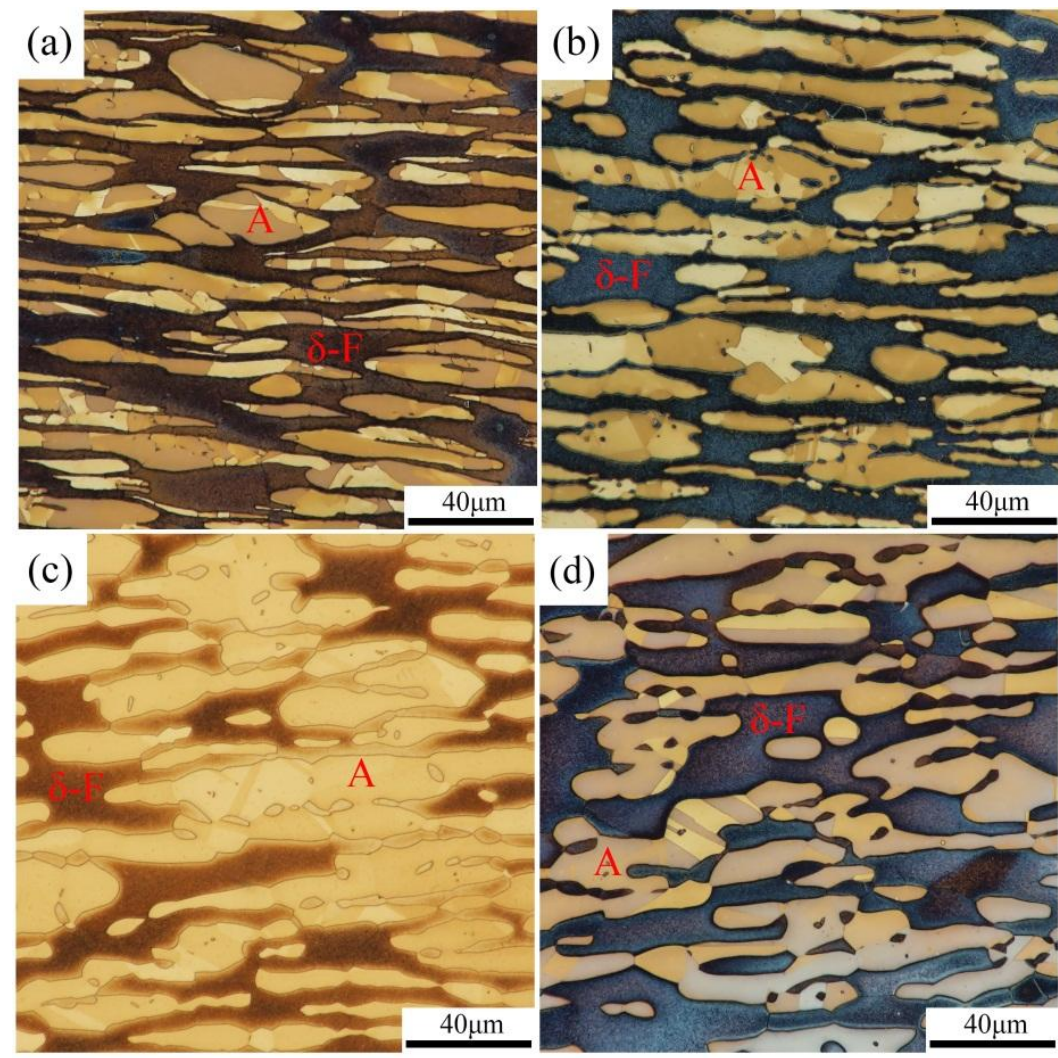

Fig. 3. Optical micrographs of 6Al steel quenched at (a) $650^{\circ} \mathrm{C}$, (b) $850^{\circ} \mathrm{C}$, (c) $950^{\circ} \mathrm{C}$, (d) $1000^{\circ} \mathrm{C}$, respectively, and then tempered at $200^{\circ} \mathrm{C}$. (A: austenite, $\delta$-F: $\delta$-ferrite)

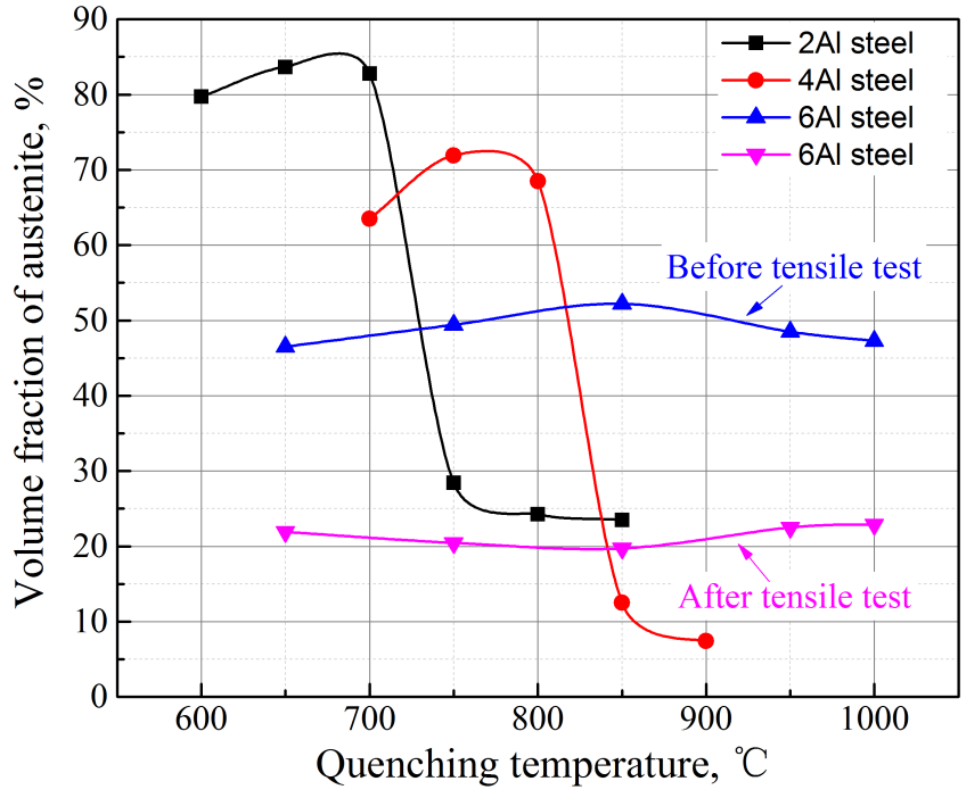

Fig. 4. Measured austenite fraction of the experimental steels as a function of quenching temperature. 

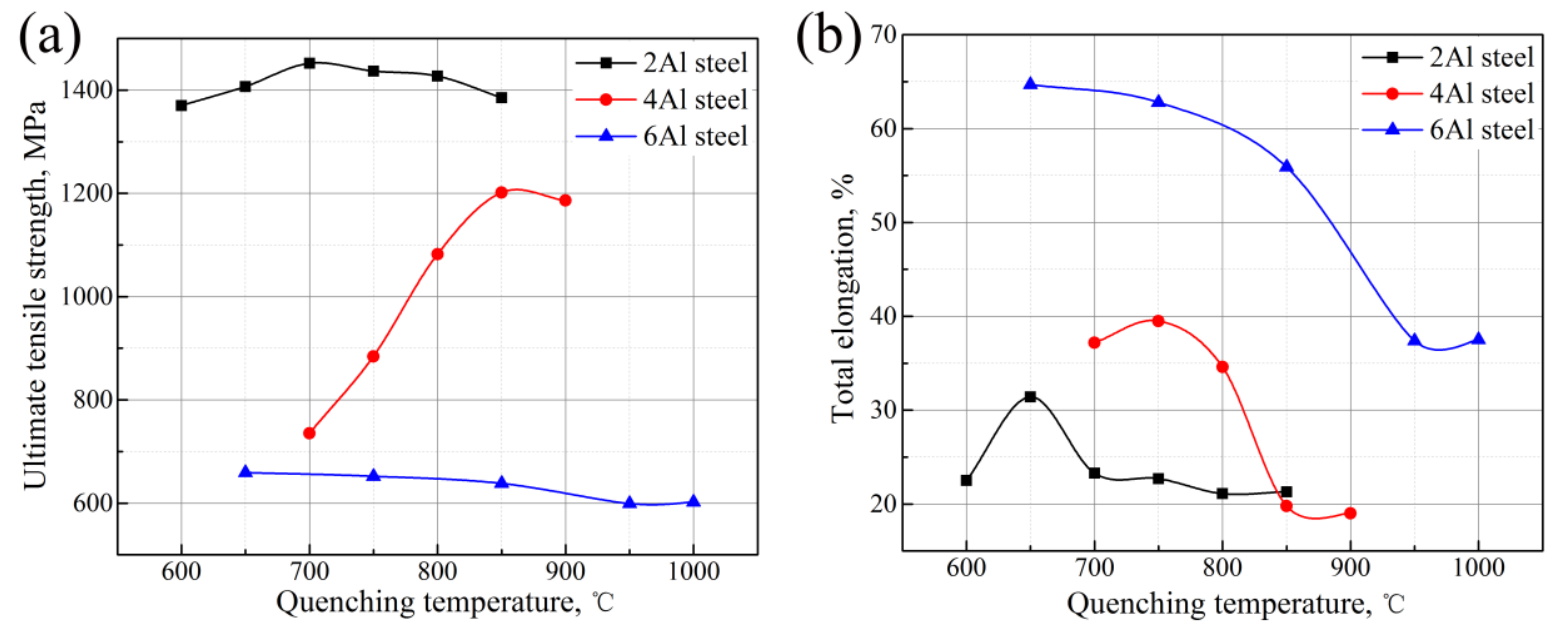

Fig. 5. Tensile properties of the three experimental steels. (a) ultimate tensile strength, (b) total elongation.
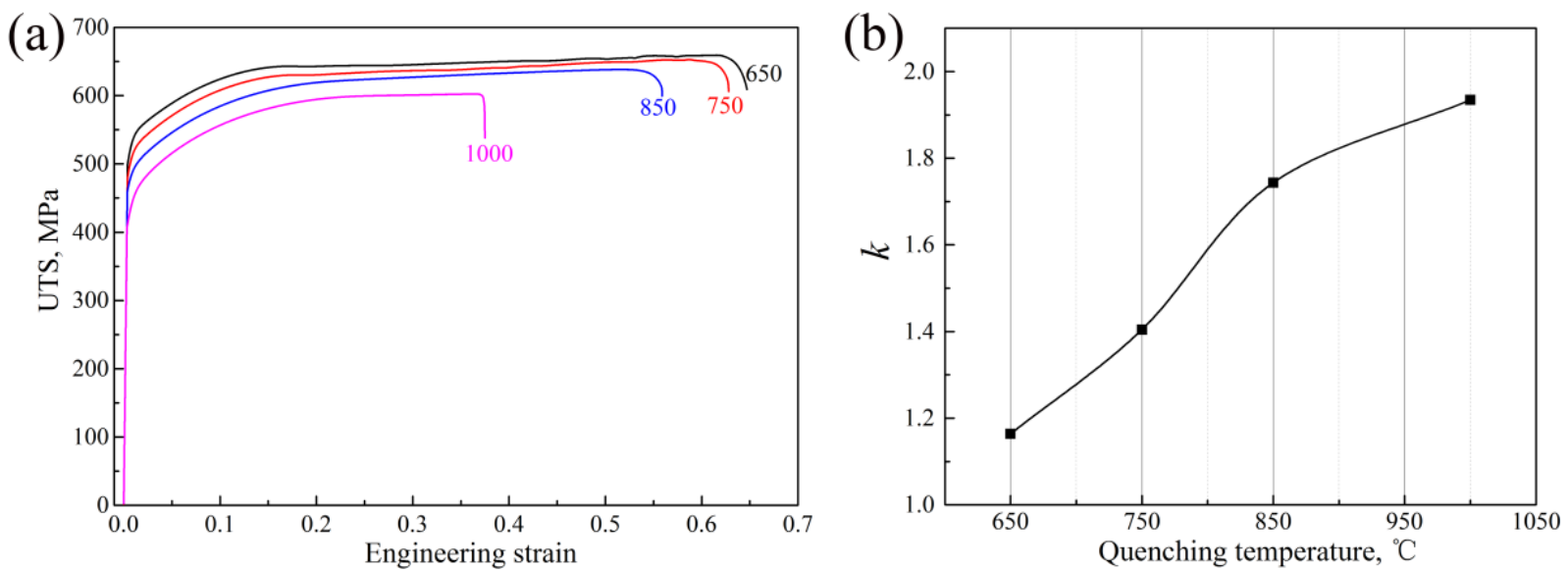

Fig. 6. Engineering strain-stress plots (a) and calculated $k$ parameter (b) of 6Al steel quenched at different temperatures. 


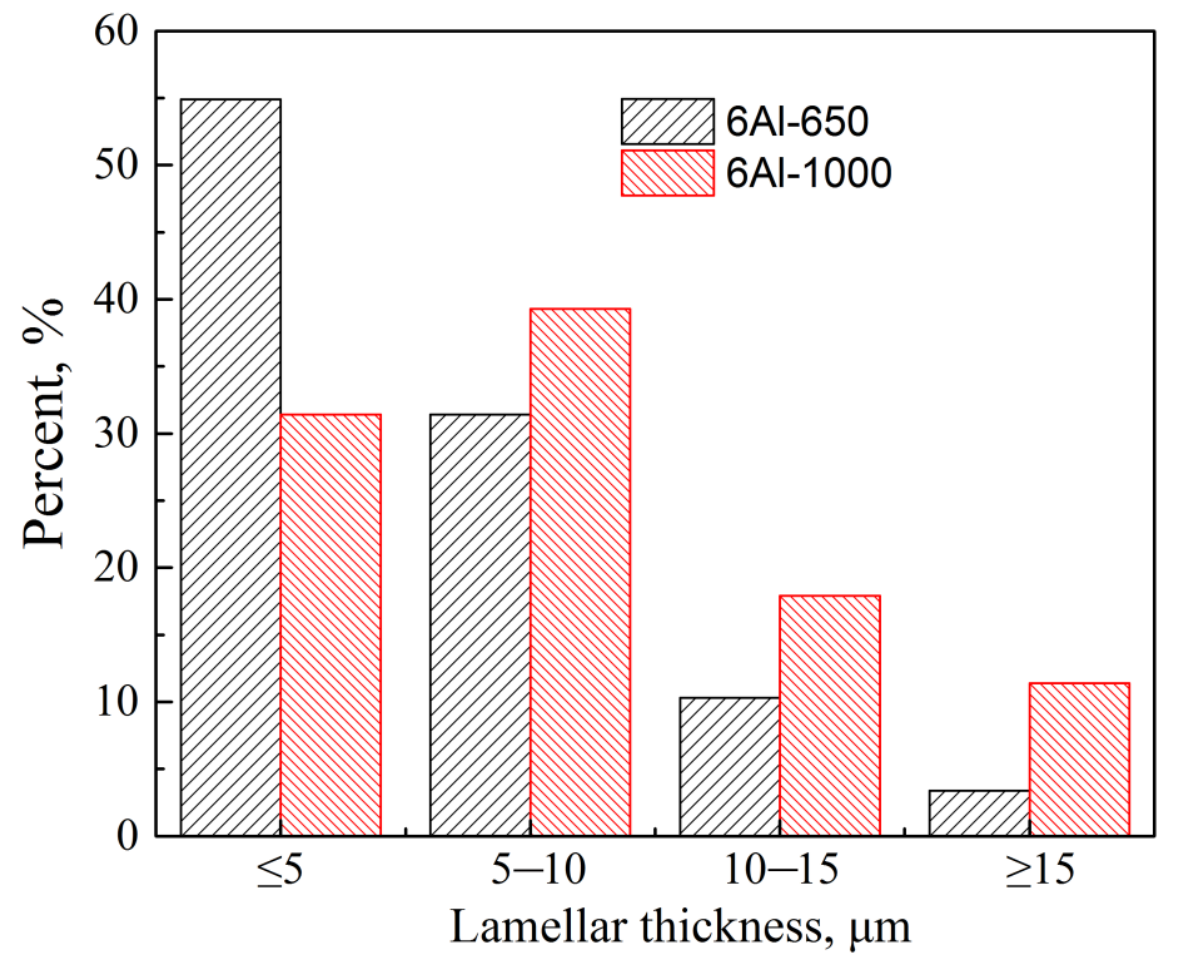

Fig. 7. The percent of the lamellar austenite as a function of lamellar thickness in 6Al-650 and 6Al-1000 samples.
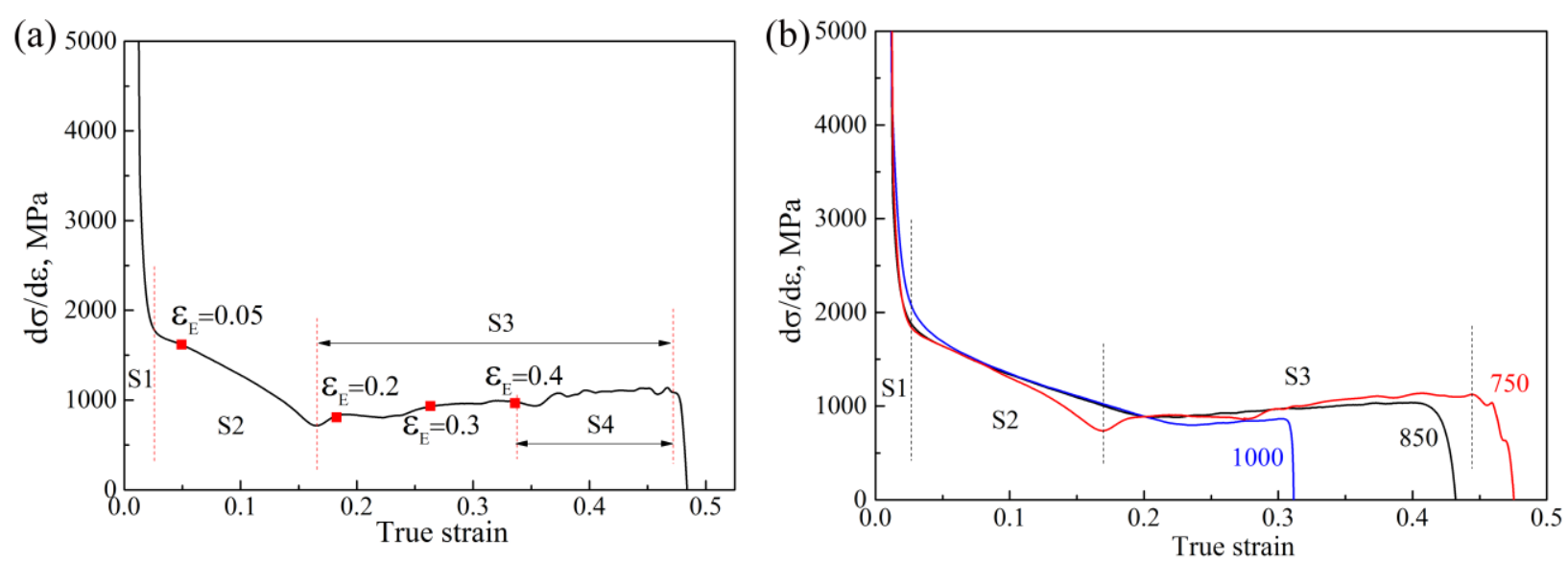

Fig. 8. Work hardening rate of $6 \mathrm{Al}$ samples quenched at different temperatures. (a) $650^{\circ} \mathrm{C}$, (b) $750^{\circ} \mathrm{C}, 850^{\circ} \mathrm{C}$ and $1000^{\circ} \mathrm{C}(\mathrm{S} 1$ : stage $1, \mathrm{~S} 2$ : stage 2 , and so on). 

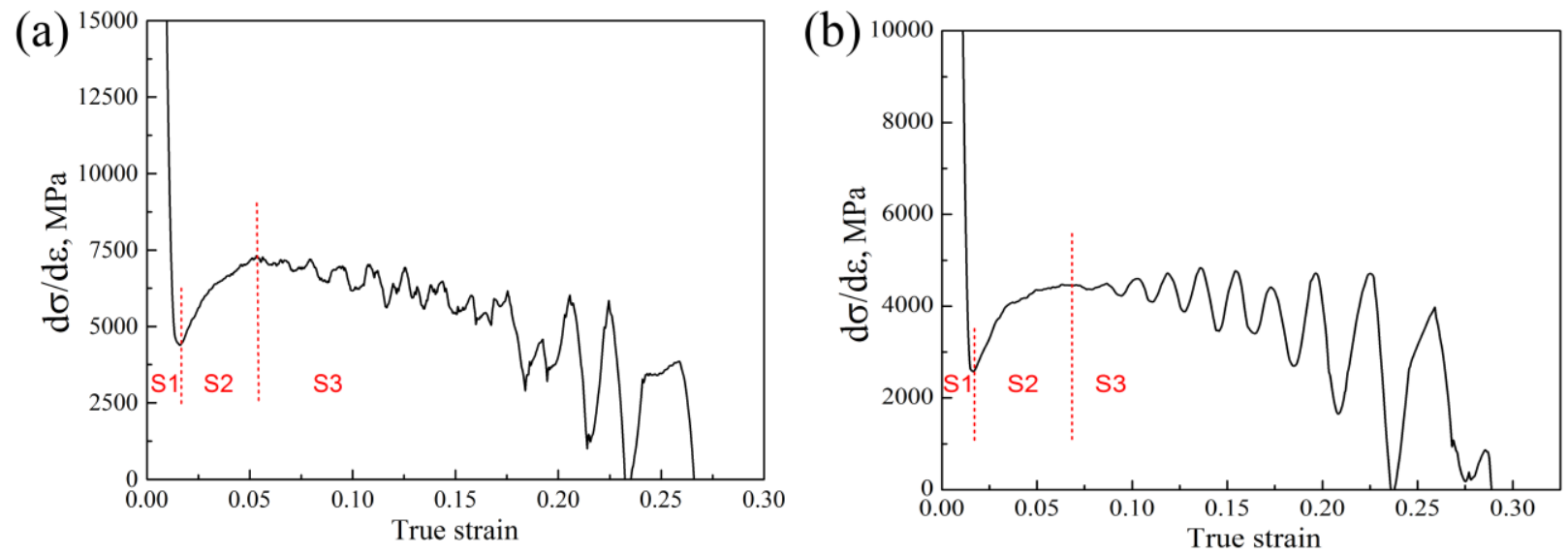

Fig. 9. Work hardening rate of 2Al-650 sample (a) and 4Al-800 samples (b) (S1: stage 1, S2: stage 2, and so on).

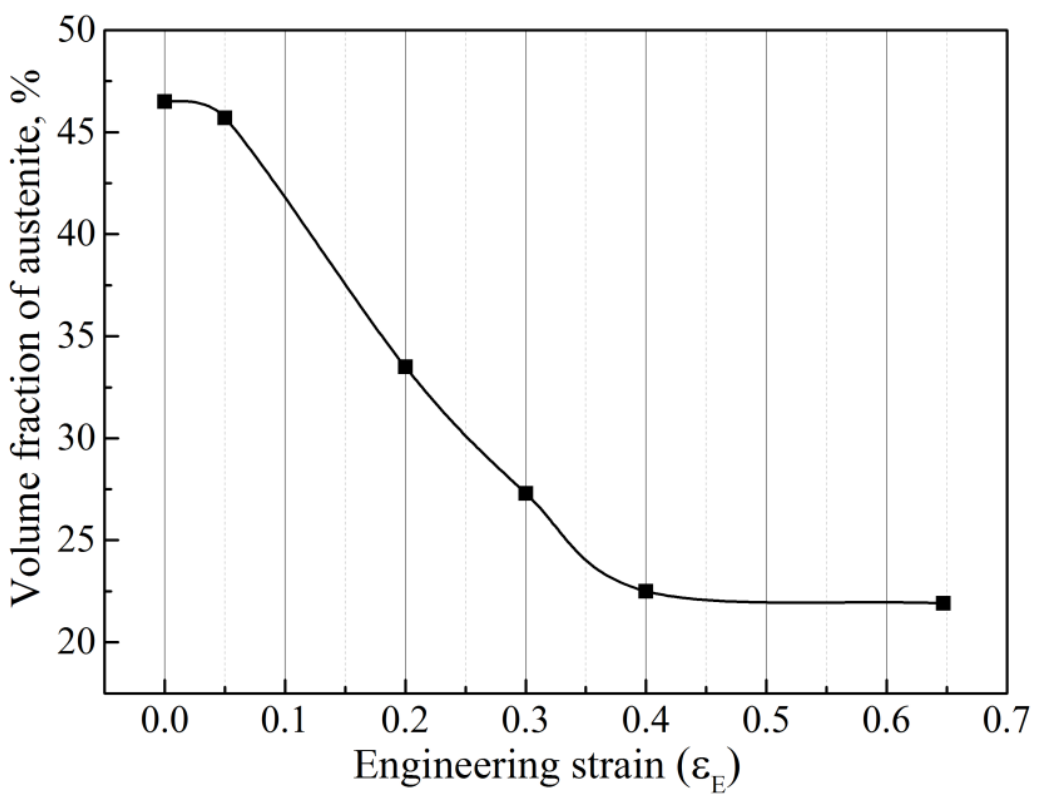

Fig.10. Variation in austenite fraction in 6Al-650 sample subjected to interrupted tensile test. 

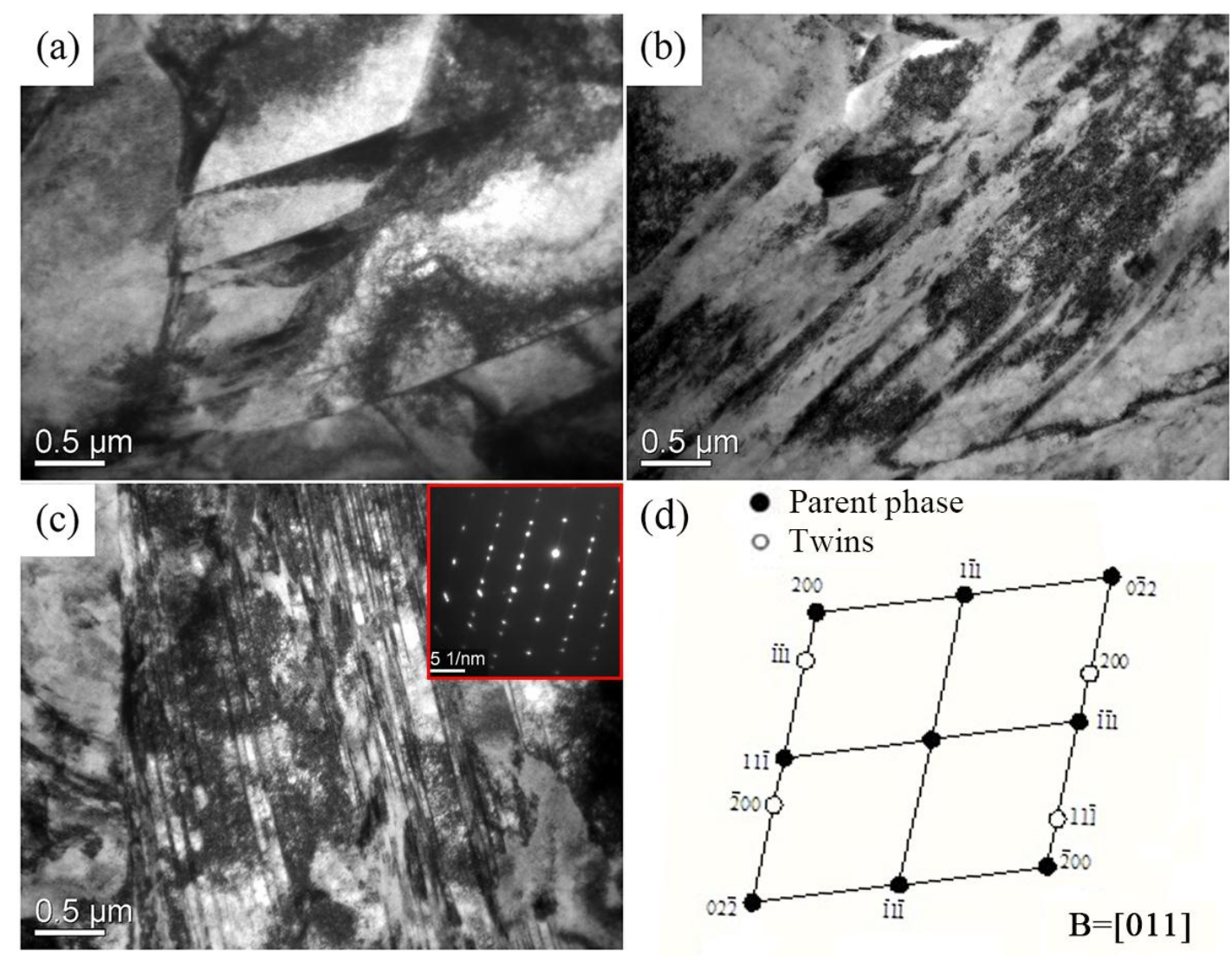

(d)

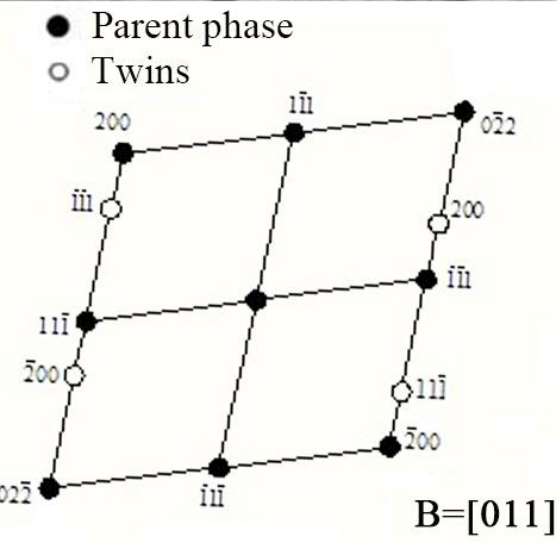

Fig. 11. TEM micrographs of 6Al-650 sample subjected to interrupted tensile test. (a) strained to 0.2 , (b) strained to 0.4 , (c) tensile fractured, (d) indexing on the spots of the selected area electron diffraction pattern of the austenite twins.
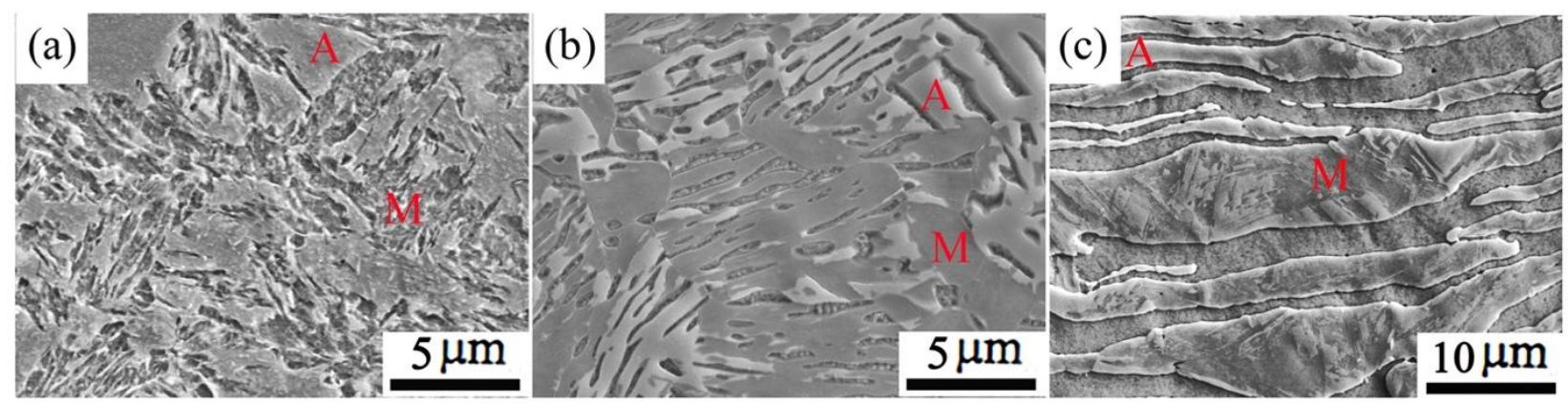

Fig.12. SEM micrographs of 2Al-650, 4Al-800 and 6Al-650 samples after tensile fracture. (a) 2Al-650, (b) 4Al-800, (c) 6Al-650. 
Table 1 Chemical composition (wt. \%) of three experimental steels

\begin{tabular}{lcccc}
\hline & $\mathrm{Mn}$ & $\mathrm{Al}$ & $\mathrm{C}$ & $\mathrm{Fe}$ \\
\hline 2Al steel & 11.20 & 1.95 & 0.22 & Bal. \\
4Al steel & 11.02 & 3.81 & 0.18 & Bal. \\
6Al steel & 10.75 & 6.08 & 0.21 & Bal. \\
\hline
\end{tabular}

Table 2 Microstructural constituents of the experimental steels

\begin{tabular}{lll}
\hline Steel No. & phase & Temperature range \\
\hline \multirow{2}{*}{$2 \mathrm{Al}$ steel } & Austenite and $\alpha$-ferrite & $600 \sim 700^{\circ} \mathrm{C}$ (two phase region) \\
& Austenite, $\alpha$-ferrite and martensite & $750 \sim 850^{\circ} \mathrm{C}$ (austenite zone) \\
\hline \multirow{2}{*}{$4 \mathrm{Al}$ steel } & Austenite, $\alpha$-ferrite and $\delta$-ferrite & $700 \sim 800^{\circ} \mathrm{C}$ (two phase region) \\
& Austenite, $\alpha$-ferrite, $\delta$-ferrite and martensite & $850 \sim 950^{\circ} \mathrm{C}$ (austenite zone) \\
\hline \multirow{2}{*}{ 6Al steel } & Austenite and $\delta$-ferrite & $650 \sim 1000^{\circ} \mathrm{C}$ \\
\hline
\end{tabular}

Table 3 Contents of alloying elements of austenite in 6Al samples

\begin{tabular}{cccc}
\hline samples & Mn (wt.\%) & Al (wt. \%) & Calculated C (wt.\%) \\
\hline 6Al-650 & 12.62 & 5.32 & 0.31 \\
6Al-850 & 12.64 & 5.18 & 0.27 \\
6Al-1000 & 12.67 & 5.57 & 0.24 \\
\hline
\end{tabular}

Table 4 Microhardness of constituent phases in different samples

\begin{tabular}{c|ccc}
\hline \multirow{2}{*}{ Sample } & & & \\
\hline 2Al-650 & $\alpha$-ferrite & $\delta$-ferrite & Austenite \\
4Al-800 & $322 \pm 20$ & none & $307 \pm 20$ \\
6Al-650 & $336 \pm 15$ & $253 \pm 6$ & $200 \pm 20$ \\
\hline
\end{tabular}

